\title{
Imperforate tricuspid valve with single cardiac outlet from right ventricle
}

\author{
W B KNIGHT, E A SHINEBOURNE \\ From the Department of Paediatric Cardiology, Brompton Hospital, London
}

SUMMARY A cyanosed neonate was diagnosed as having concordant atrioventricular connection and single cardiac outlet and aorta from right ventricle with atresia of the pulmonary valve. She underwent a systemic to pulmonary artery shunt and is now thriving. Additionally, the tricuspid valve was imperforate and a large ventricular septal defect caused an unusual pattern of intracardiac blood flow. The tricuspid valve ring and right ventricular cavity appeared to be of normal size. The good outcome in this patient suggests that these features may be advantageous for corrective operation.

Two different forms of tricuspid atresia have been reported. ${ }^{1}$ These are a univentricular atrioventricular connection with absence of the right atrioventricular ostium (classic "tricuspid atresia") and a biventricular atrioventricular connection with an imperforate tricuspid valve. The latter is much less frequent and is usually associated with right ventricular hypoplasia. The abnormal ventriculoarterial connection in the present case resulted in a convoluted blood flow pattern and was associated with an unusually well developed tricuspid valve annulus and right ventricle.

\section{Case report}

A $4.2 \mathrm{~kg}$ full term female infant was centrally cyanosed from 12 hours of age. Abnormal findings were a single second heart sound and a $2 / 6$ ejection systolic murmur at the left sternal edge. No separate ductal murmur was audible despite an infusion of prostaglandin $\mathrm{E}_{2}$. Arterial $\mathrm{Po}_{2}$ was $3.8 \mathrm{kPa}$ in air and $6.8 \mathrm{kPa}$ in $100 \%$ oxygen. The electrocardiogram showed sinus rhythm with normal $P$ waves, a QRS axis of $+20^{\circ}$ and left ventricular dominance, and the

Requests for reprints to Dr W B Knight, Department of Cardiology, Adelaide Children's Hospital, 72 King William Road, North Adelaide, South Australia 5006, Australia. chest radiograph showed reduced perfusion of the lungs.

Cross sectional echocardiography showed normal arrangement of the abdominal great vessels, normal venous return, concordant atrioventricular connection, and probable double outlet right ventricle, with the large aorta arising anterior and to the right of the atretic pulmonary valve and small pulmonary trunk. The branch pulmonary arteries were small. A left aortic arch and large arterial duct were present. The right ventricle was of normal size and communicated with the left ventricle via a large perimembranous ventricular septal defect (fig 1a). A muscular defect was also seen. A mobile but imperforate membrane was seen between the right atrium and ventricle. There was at least one chordal attachment from the ventricular surface of the valve to the interventricular septum (fig 1b). Doppler echocardiography did not detect flow across the valve. The pattern of interatrial flow was readily appreciated by visualisation of the margins of the foramen ovale which opened widely into the left atrium during each diastole and showed a biphasic leftward movement that mirrored the movement of the mitral valve.

A right modified Blalock shunt was constructed with a $4 \mathrm{~mm}$ diameter polytetrafluoroethylene tube. 

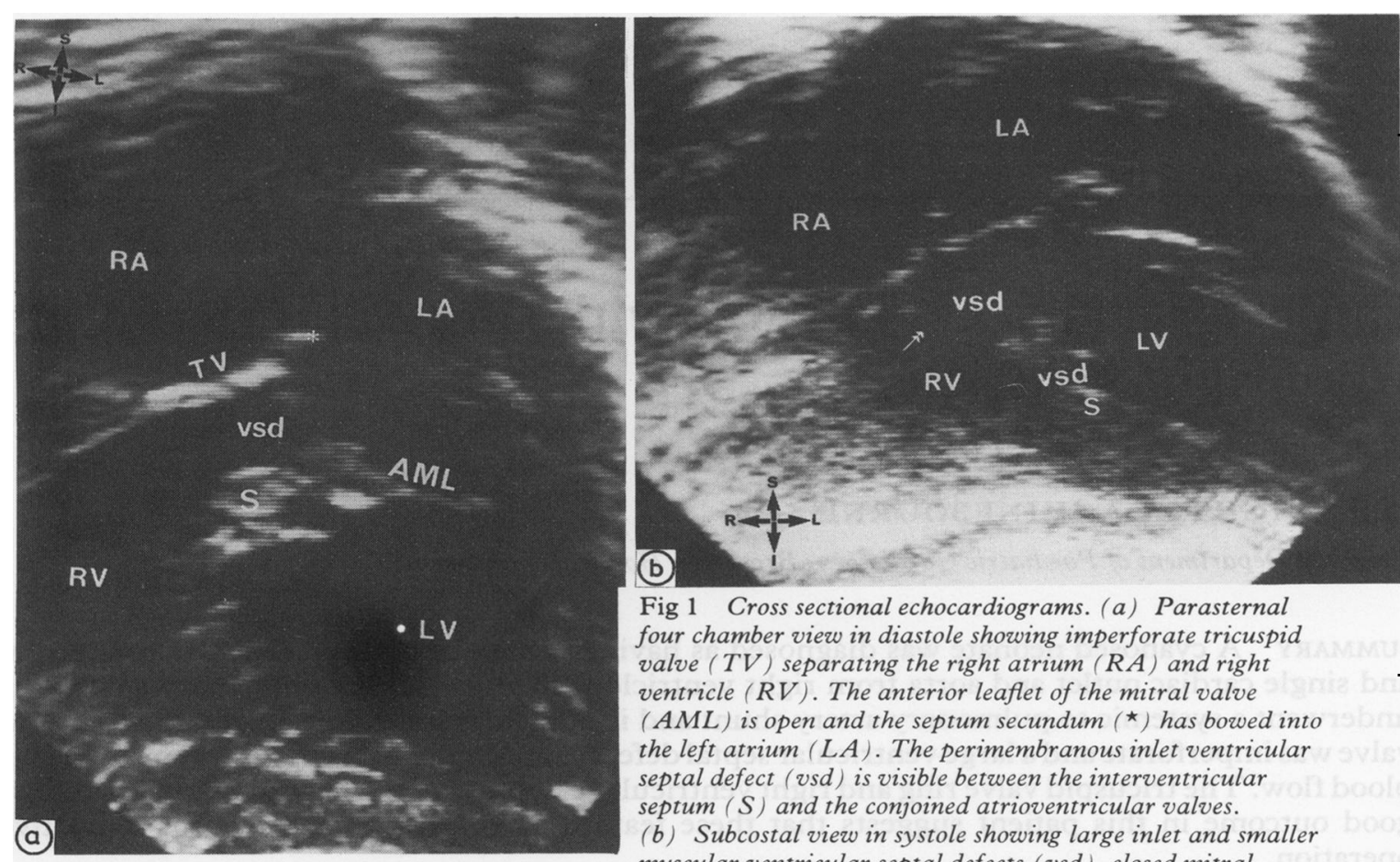

Fig 1 Cross sectional echocardiograms. (a) Parasternal four chamber view in diastole showing imperforate tricuspid valve ( $T V$ ) separating the right atrium ( $R A$ ) and right ventricle $(R V)$. The anterior leaflet of the mitral valve $(A M L)$ is open and the septum secundum (*) has bowed into the left atrium $(L A)$. The perimembranous inlet ventricular septal defect (vsd) is visible between the interventricular septum $(S)$ and the conjoined atrioventricular valves.

(b) Subcostal view in systole showing large inlet and smaller muscular ventricular septal defects (vsd), closed mitral valve, and imperforate tricuspid valve with tensor apparatus (double-headed arrow).
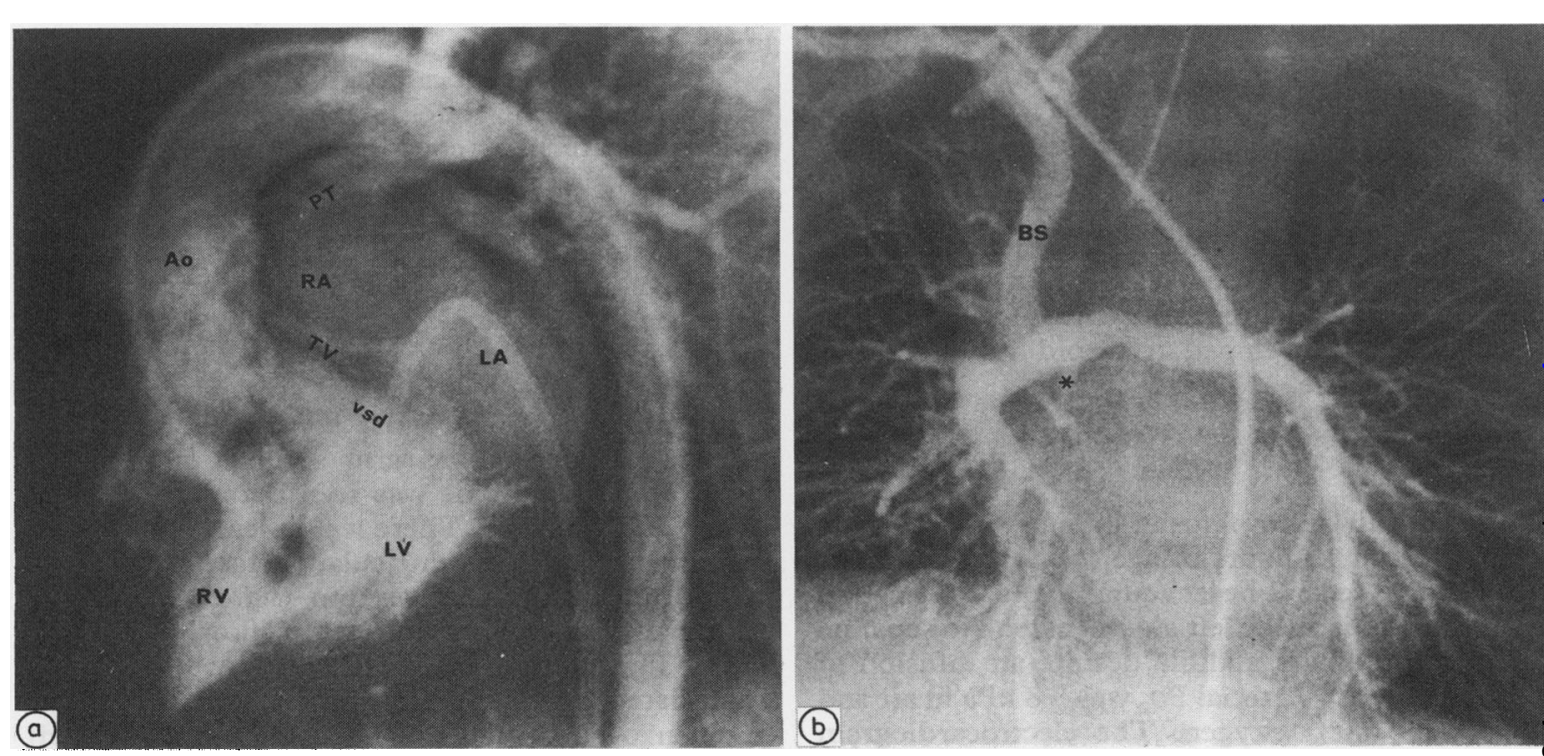

Fig 2 (a) Left ventriculogram in a four chamber projection showing the large inlet ventricular septal defect (VSD) and normal sized right ventricle (RV). Mitral regurgitation induced by extra systoles resulted in contrast washing back via the left atrium ( $L A$ ) into the right atrium (RA). The imperforate tricuspid valve $(T V)$ is clearly profiled between the right atrium and ventricle. The aorta (Ao) arises from the right ventricle. The narrow, blind-ending pulmonary trunk (PT) filled retrogradely via the shunt. $L V$, left ventricle. (b) A subclavian arteriogram showing filling of the modified Blalock shunt $(B S)$, the right and left pulmonary arteries, and the blind-ending, right sided pulmonary trunk (*). 
Her colour improved but she remained mildly tachypnoeic. Cardiac catheterisation was therefore performed at the age of seven weeks. The mean right and left atrial pressures were 5 and $4 \mathrm{~mm} \mathrm{Hg}$ respectively. Simultaneously measured left ventricular and ascending aortic systolic pressures were equal. There was an atrial right to left shunt with equal left atrial and aortic oxygen saturations $(82 \%)$. When contrast was injected into the right atrium it passed without hold-up into the left atrium and then into the left ventricle, right ventricle, ascending aorta, and finally via the patent shunt into the pulmonary arteries. The same injection also showed left juxtaposition of the atrial appendages. Left ventriculography (fig 2a) showed the perimembranous ventricular septal defect and confirmed that there was no arterial outlet from this chamber. Extrasystoles induced mitral regurgitation which resulted in reflux of contrast into the left atrium and then the right atrium. The imperforate tricuspid valve was thus outlined between the right atrium and ventricle. An injection of contrast into the shunt showed equal filling of rather small pulmonary arteries and outlined the small blind-ending pulmonary trunk (fig $2 \mathrm{~b}$ ). Pulmonary venous return was normal. Thus no further surgical intervention was required. Her breathing and weight gain are now normal.

\section{Discussion}

In classic tricuspid atresia the right atrioventricular connection is absent and this entity is far more frequent than an imperforate tricuspid valve. ${ }^{1}$ An imperforate tricuspid valve must be distinguished from the imperforate form of Ebstein's anomaly ${ }^{2}$ and from the imperforate right side of a common valve in complete atrioventricular septal defect. ${ }^{3}$ All are rare. As in the present case, cross-sectional echocardiography facilitates the diagnosis, especially when the imperforate valve is thin and mobile and a hypoplastic tensor apparatus is seen. ${ }^{4}$

An imperforate tricuspid valve is always accompanied by other lesions. Usually the right ventricle and tricuspid annulus are hypoplastic and there is pulmonary stenosis or atresia with or without a small ventricular septal defect ${ }^{24}$ or absence of the pulmonary valve. ${ }^{5}$ Dickinson $e t$ al described three hearts with an imperforate tricuspid valve, ventricular septal defect, and discordant ventriculoarterial connection; but in all the inlet portion of the right ventricle was hypoplastic. ${ }^{6}$ In an anatomical study Wilkinson et al reported a single case of imperforate tricuspid valve associated with double outlet right ventricle but they gave no details.
As far as we are aware the present case is the first description of an imperforate tricuspid valve and single cardiac outlet from the right ventricle. In contrast to previous cases of imperforate tricuspid valve, the tricuspid annulus and, accordingly, the inlet portion as well as the trabecular and outlet portions of the right ventricle are of normal size. These features may be related to a flow pattern resulting from lack of an arterial outlet from the left ventricle and a large ventricular septal defect. The right ventricle in this case in an indispensable link in the tortuous passage of blood from the veins to great arteries.

Surgical palliation was remarkably successful. Future corrective operation may include closure of the ventricular septal defect with incorporation of the aorta into the left ventricle, and construction of a right ventricle to pulmonary artery conduit-in addition to excision of the tricuspid valve and the placement of a tricuspid valve prosthesis.

\section{References}

1 Anderson RH, Wilkinson JL, Gerlis LM, Smith A, Becker AE. Atresia of the right atrioventricular orifice. Br Heart J 1977;39:414-28.

2 Van Praagh R, Ando M, Dungan WT. Anatomic types of tricuspid atresia: clinical and developmental implications [Abstract]. Circulation 1971;44(suppl 2):115.

3 Van Praagh R. Discussion of Vlad P: Pulmonary atresia with intact ventricular septum: In: Barratt-Boyes BG, Neutze JM, Harris EA, eds. Heart disease in infancy: diagnosis and surgical treatment. Proceedings of the Second International Symposium held at Green Lane Hospital, Auckland, New Zealand, February 1972. Edinburgh: Churchill Livingstone, 1973: 246-7.

4 Rigby ML, Gibson DG, Joseph MC, et al. Recognition of imperforate atrioventricular valves by two dimensional echocardiography. $\mathrm{Br}$ Heart $J$ 1982;47:329-36.

5 Freedom RM, Patel RG, Bloom KR, et al. Congenital absence of the pulmonary valve associated with imperforate membrane type of tricuspid atresia, right ventricular tensor apparatus and intact ventricular septum: a curious developmental complex. Eur J Cardiol 1979;3:171-96.

6 Dickinson DF, Wilkinson JL, Smith A, Anderson RH. Atresia of the right atrioventricular orifice with atrioventricular concordance. Br Heart J 1979;42: 9-14.

7 Wilkinson JL, Wilcox BR, Anderson RH. Anatomy of double outlet right ventricle. In: Anderson RH, Macartney FJ, eds. Paediatric cardiology 5. Edinburgh: Churchill Livingstone, 1983:402. 